\title{
Persistence of stapedial artery: a case report*
}

Persistência da artéria estapedial artery: relato de caso

\author{
Bruna Vilaça de Carvalho ${ }^{1}$, Juliana Oggioni Gaiotti ${ }^{1}$, Renata Lopes Furletti Caldeira Diniz ${ }^{2}$, \\ Marcelo Almeida Ribeiro ${ }^{2}$, Emília Guerra Pinto Coelho Motta $^{2}$, Wanderval Moreira ${ }^{2}$
}

\begin{abstract}
Persistent stapedial artery is a rare congenital anomaly that occurs by a failure in the involution of such artery. Most patients with persistent stapedial artery are asymptomatic. The imaging diagnosis is made principally by means of multidetector computed tomography. In the present case, persistent stapedial artery was an incidental computed tomography finding. The authors discuss the embryogenesis, computed tomography findings and the importance of an early diagnosis of such anomaly.
\end{abstract}

Keywords: Persistent stapedial artery; Congenital; Tomography.

Resumo A artéria estapedial persistente é uma rara anomalia congênita que ocorre por uma falha na sua involução. A maioria dos pacientes com artéria estapedial persistente é assintomática. 0 diagnóstico de imagem é feito principalmente pela tomografia computadorizada multidetectores. Neste estudo a artéria estapedial persistente foi um achado ocasional no exame tomográfico. São discutidos a embriologia, os achados tomográficos e a importância do seu diagnóstico precoce. Unitermos: Artéria estapedial persistente; Congênita; Tomografia.

Carvalho BV, Gaiotti JO, Diniz RLFC, Ribeiro MA, Motta EGPC, Moreira W. Persistence of stapedial artery: a case report. Radiol Bras. 2013 Mai/Jun;46(3):184-186.

\section{INTRODUCTION}

Persistent stapedial artery (PSA) is a rare congenital anomaly, with prevalence calculated to be of $0.02 \%-0.05 \%{ }^{(\mathbf{1})}$ in surgical series and of $0.48 \%$ in temporal bone studies $^{(2)}$. The stapedial artery is a vascular structure that is transiently present during the developmental stage of a fetus where it makes anastomosis between the external and internal branches of the carotid arteries. During the normal embryogenesis, the stapedial artery atrophies at the third gestational month.

The imaging diagnosis may be made by means of multidetector computed tomography or by angiography. Magnetic resonance imaging as well as magnetic resonance angiography play a limited role in the diagnosis of PSA, because of the reduced dimensions of the stapedial artery (diameter between 1.5 and $2.0 \mathrm{~mm})^{(3)}$.

* Study developed in the Unit of Radiology and Imaging Diagnosis - Hospital Mater Dei, Belo Horizonte, MG, Brazil.

1. MDs, Trainees of Radiology and Imaging Diagnosis Hospital Mater Dei, Belo Horizonte, MG, Brazil.

2. MDs, Radiologists, Hospital Mater Dei, Belo Horizonte, MG, Brazil.

Mailing Address: Dra. Bruna Vilaça de Carvalho. Rua Alagoas, 904, ap. 1204, Savassi. Belo Horizonte, MG, Brazil, 30130-160. E-mail: brunavilaca@gmail.com.

Received September 27, 2012. Accepted after revision January 11, 2013.

\section{CASE REPORT}

Female, 50-year-old patient complaining of left hypoacusis for three months. The patient denied sonitus and dizziness. There was no positive family history for ear diseases or trauma/surgery involving such site.

Audiometry study evidenced left-sided hearing loss, without air-bone gap. Multislice computed tomography demonstrated

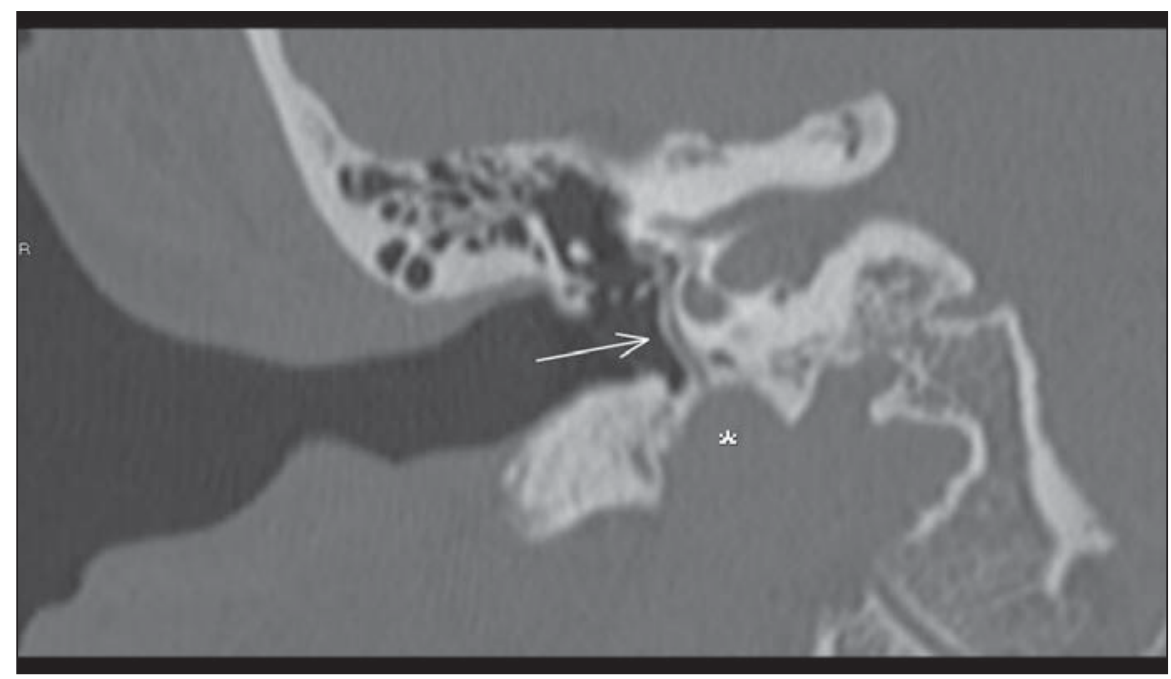

Figure 1. Multislice computed tomography image with coronal reconstruction. Persistent stapedial artery (arrow) originating from the internal carotid artery (asterisk), with an ascending course adjacent to the cochlear promontory, passing through the oval window. the presence of a subtle, apparently vascular, tube-shaped structure originating from the vertical segment of the internal carotid artery at right, with an ascending course along the cochlear promontory, crossing the oval window (Figure 1), passing adjacent to the stapes crura (Figure 2) towards the middle cranial fossa, with enlargement of the anterior tympanic segment of the facial nerve (Figure 3). Associated absence of the 


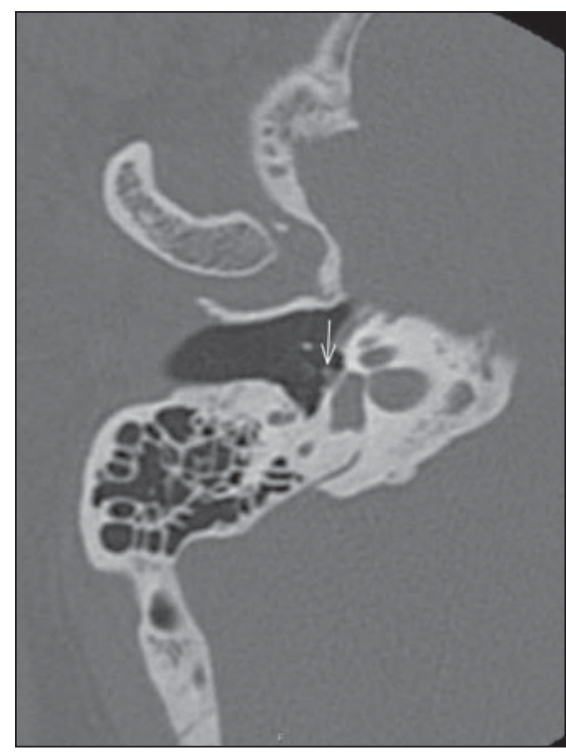

Figure 2. Axial multislice computed tomography. Persistent stapedial artery (arrow) adjacent to the anterior crura and to the stapes footplate.

ipsilateral spinous foramen was observed, which is compatible with PSA. No evidence of association with aberrant carotid artery was observed. No significant alteration was observed in the side ipsilateral to the reported symptoms.

\section{DISCUSSION}

The embryonic stapedial artery persists because of a failure in its involution. Such artery is an integral part of the second brachial arch and originates from the hyoid artery that is a branch of the internal carotid artery. Then, it extends cranially and passes through the mesenchymal primordium of the stapes, forming the obturator foramen

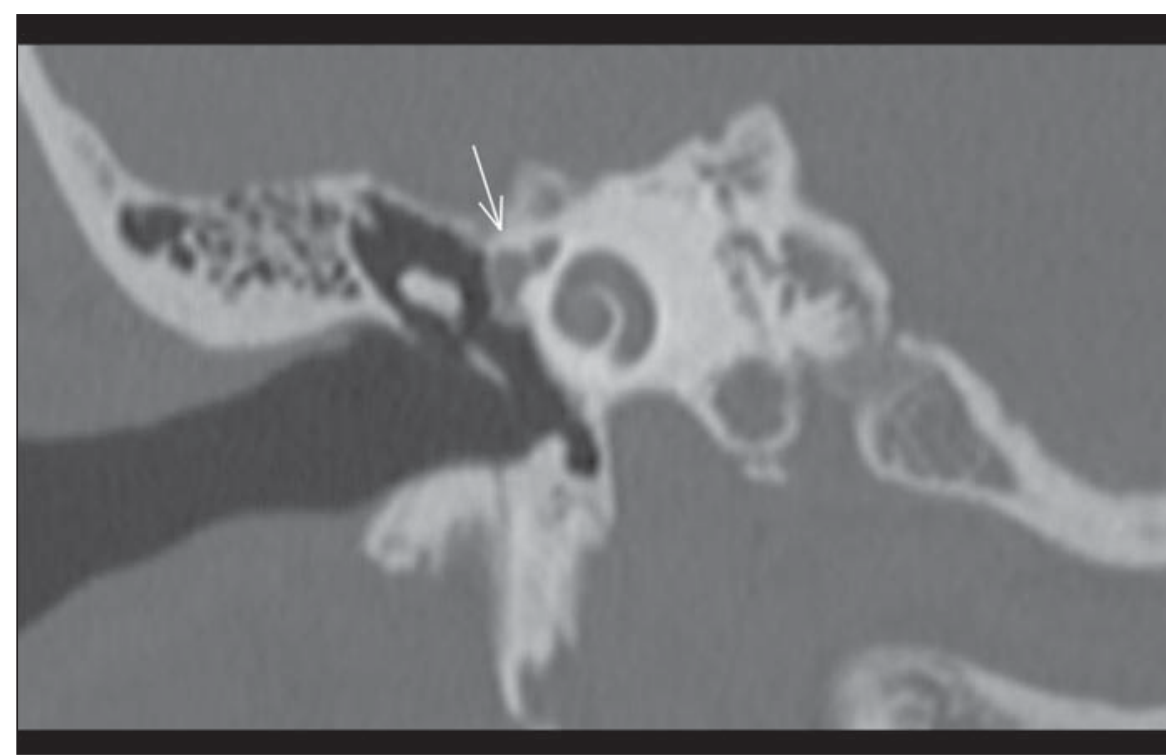

Figure 3. Multislice computed tomography image with coronal reconstruction. Asymmetry between the labyrinthic and tympanic segments of the facial nerve, with enlargement of the latter (arrow).

of the stapes ${ }^{(3)}$, becoming the middle meningeal artery, in the extradural region of the middle cranial fossa ${ }^{(4)}$. When the stapedial artery fails to involute, it originates the middle meningeal artery, and the spinous foramen that normally includes de middle meningeal artery will be absent (Figure 4).

In most of times, patients with PSA are asymptomatic, but reports about cases of conductive hypoacusis, sonitus, retrotympanic pulsatile mass and, rarely, neurosensory hearing loss are found in the literature $^{(5)}$. Also, such condition has been associated with other diseases such as trisomy 13, 15 and 21, Paget's disease, otosclerosis, anencephaly, congenital immunodeficiency and neurofibromatosis ${ }^{(\mathbf{4 , 5})}$.
For an accurate detection of such vascular anomaly, it is important to know the persistent stapedial artery trajectory. Its course is typical, originating from the petrous segment of the internal carotid artery, entering anteromedially into the hypotympanum, coursing adjacent to the promontory and then cranially, through the obturator foramen of the stapes, entering into the facial nerve canal through a dehiscence right behind the cochleariform process ${ }^{(3,4)}$. The stapedial artery courses anteriorly to the facial nerve canal and leaves the canal immediately before the geniculate ganglion and continuing through the extradural space in the middle cranial fossa. In the literature, there are reports of cases where the

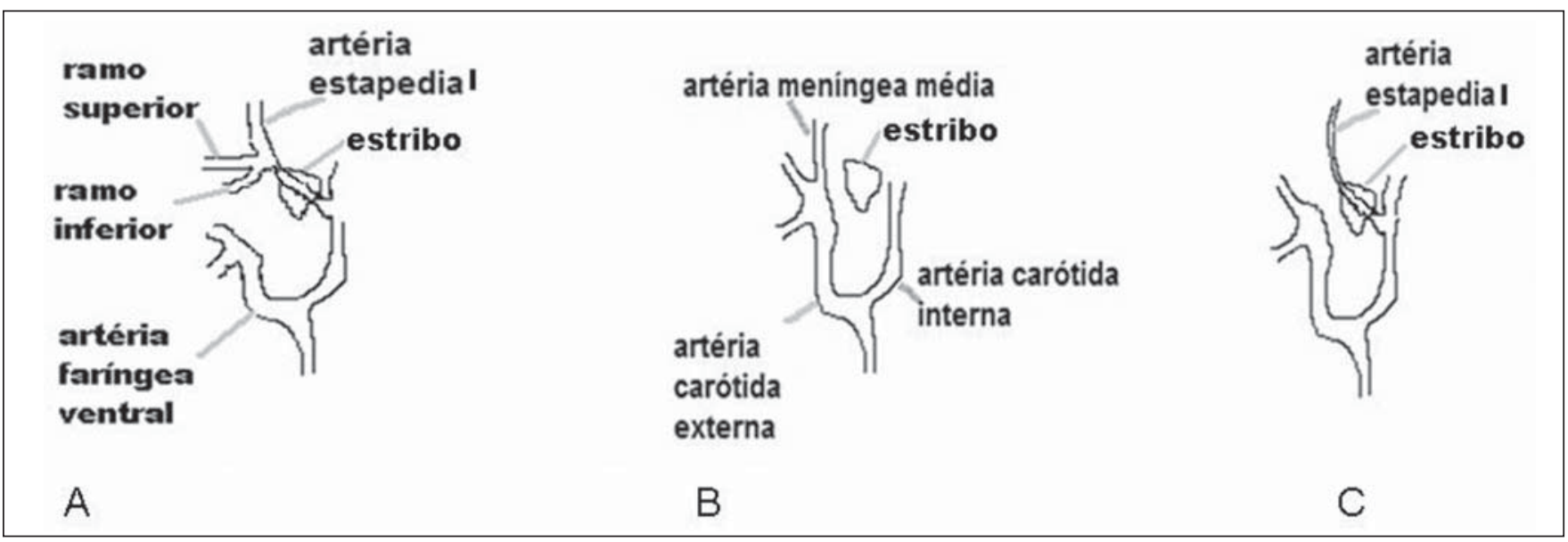

Figure 4. Normal embryological development of the stapedial artery $(\mathbf{A}, \mathbf{B})$ and anatomical variation with persistent stapedial artery $(\mathbf{C})$. 
stapedial artery may either course through a canal parallel to the facial nerve or extend into such canal, through a short segment ${ }^{(5)}$.

The tomographic findings suggestive of this anomaly are the following: 1) small canaliculus originating from the carotid canal; 2) linear structure passing through the middle ear space, adjacent to the promontory; 3) enlargement of the tympanic segment of the facial nerve canal or a separate canal paralleling the facial nerve; 4) absence of the spinous foramen ${ }^{(4,5)}$. Such condition may be associated with other abnormalities involving the stapes, the facial nerve and the internal carotid artery. The association with aberrant internal carotid artery is the most common association ${ }^{(5-7)}$.

Intraoperative or post-mortem diagnosis of such abnormality has been a rule ${ }^{(5)}$. However, with the progress in imaging methods, the rate of early detection of such abnormality has increased. The radiologist plays a fundamental role in the diagnosis of this vascular anomaly, aiding in the differential diagnosis of facial nerve tumors and in the surgical planning.

The previous knowledge of the anomaly by the otorhinolaryngologist allows the coagulation of this malformation with laser, facilitating the surgery and avoiding complications $^{(\mathbf{8})}$.

Persistent stapedial artery does not require treatment, except in cases of intense sonitus, where endovascular ligation can be performed.

\section{REFERENCES}

1. Stott CC, Royer MF, Olmedo RO, et al. Resultados auditivos de estapedostomías en platinas complicadas. Rev Otorrinolaringol Cir Cabeza Cuello. 2006;66:89-94.
2. Jain R, Gandhi D, Gujar S, et al. Case 67: Persistent stapedial artery. Radiology. 2004;230:413-6.

3. Silbergleit R, Quint DJ, Mehta BA, et al. The persistent stapedial artery. AJNR Am J Neuroradiol. 2000;21:572-7.

4. Thiers FA, Sakai O, Poe DS, et al. Persistent stapedial artery: CT findings. AJNR Am J Neuroradiol. 2000;21:1551-4.

5. Dimmick SJ, Faulder KC. Normal variants of the cerebral circulation at multidetector CT angiography. Radiographics. 2009;29:1027-43.

6. Moreno BA, García AU, Sampériz LC, et al. Carótida interna aberrante como causa de tumoración pulsátil en el oído médio. ORL ARAGON. 2010; 13:14-6.

7. Shimizu S, Sasahara G, Iida Y, et al. Aberrant internal carotid artery in the middle ear with a deficiency in the origin of the anterior cerebral artery: a case report. Auris Nasus Larynx. 2009;36:35962.

8. Breheret R, Bizon A, Tangur JY, et al. Persistent stapedial artery with otosclerosis. Ann Otolaryngol Chir Cervicofac. 2009;126:259-63. 